\title{
On Mr. C. W. Siemens's new theory of the sun
}

\section{M.G.A. Hirn}

To cite this article: M.G.A. Hirn (1882) On Mr. C. W. Siemens's new theory of the sun, Philosophical Magazine Series 5, 14:90, 478-480, DOI: 10.1080/14786448208628447

To link to this article: http://dx.doi.org/10.1080/14786448208628447

$$
\text { 册 Published online: } 28 \text { Apr } 2009 .
$$

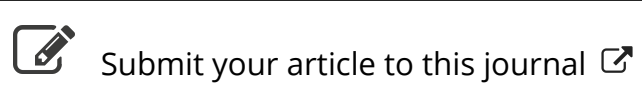

\footnotetext{
Џ Article views: 2
}

Q View related articles $₫$ 
structure of which was fully described) undoubtedly Archæan, and probably rather early in that division. The rocks of the micaceous group have considerable resemblance to the greenish and leadcoloured schists of Holyhead Island and the adjoining mainland of Anglesey, and of the Menai Strait.

Two outlying areas of serpentine, omitted in his former paper, were described-one at Polkerris, the other at Porthalla. The latter shows excellent junctions, and is clearly intrusive in the schist. The author stated that he had reexamined a large part of the district described in his former paper, and had obtained additional evidence of the intrusion of the serpentine into the sedimentary rock with which it is associated. This evidence is of so strong a nature that he could not conceive the possibility of any one who would carefully examine the district for himself entertaining a doubt upon the matter.

2. "Notes on some Upper Jurassic Astrorhizidæ and Lituolidæ." By Dr. Rudolf Häusler, F.G.S.

LIV. Intelligence and Miscellaneous Articles.

ON MR. C. W. SIEMENS'S NEW THEORY OF THE SUN. BY M. G. A. HIRN.

TO the grave objection brought forward by M. Faye against Mr. Siemens's new theory of the conservation of the solar energy, another, also a very serious one, may be added. This objection may be summed up in few words.

Up to the present time there is no general agreement as to the real value of the Sun's temperature. Père Secchi carried it to millions of degrees. Other physicists, especially in France, lowered it to about twenty thousand degrees. According to the magnificent experiments of Mr. Langley (of Alleghany) this latter amount is, at any rate, $a$ minimum. What is certain then, starting from the fine memoirs upon dissociation of our lamented colleague Henri Sainte-Claire Deville, s that none of the chemical compounds that we know upon our Earth could exist at the surface of the Sun. All, even those which are most refractory in our laboratories, would be dissociated and reduced to their constituent elements. And this is what is admitted in M. Faye's theory of the Sun.

The natural and direct consequence of the preceding fact is, that the chemical compounds which Mr. Siemens supposes to be dissociated by degrees in space by the solar radiation, might certainly, in returning under the action of gravity and in the elementary state towards the central body, become reformed, and regenerate the heat expended in their dissociation in space; but this recombination could only be effected at an appreciable distance from the solar photosphere, and the compounds reproduced, on falling into the boson of the latter, would be again completely dissociated. This action, therefore, would cause the expenditure of all the heat 
previously developed by the combination. From this it follows evidently that this return of the elements towards the centre would contribute nothing at all towards the conservation, or rather the continuous reproduction, of the solar temperature.

It seems to me that Mr. Siemens's theory may be subjected to another decisive critical test. If the solar radiation, or say the heat, whether visible or not, emitted or sent off by any celestial body, during its course effects the chemical dissociation of the hypothetical componnds disseminated in stellar space, the intensity of this radiation must necessarily be rednced by the positive work effected, and all that serves for this work is lost for the visibility of the star.

From this, then, it follows that the lustre of the sun, of the stars, and of the planets must diminish according to a much more rapid law than that of the inverse proportion of the square of the distances. I say much more rapid; but we must say extremely rapid. In fact, from the moment when the recombination of the elements at the surface of the Sun would be capable of regenerating the heat emitted, it is evident that all this emitted heat would be employed in its turn in dissociating the chemical compounds in space. In order that the Sun could be thus continually maintained in its energy, it would be necessarv that the distance at which it is visible, far from being unlimited as it probably is, should, on the contrary, be restricted; for wherever it wonld be still visible there would be light not employed in chemical dissociation, and consequently there would still be a definite loss possible. Nothing in the aspect of our planets and their satellites, it seems to me, authorizes us to assume that there is any other reduction in the brilliancy of the light than that resulting from the inverse proportion of the square of their distance from the central body. We see stars the light of which has taken at least three years, and others of which the light has perhaps taken thousands of years to reach us. None of this light, therefore, has been employed in chemical dissociation; nothing could have been restored to them by the mode indicated by the ingenious theory of $\mathrm{Mr}$. Siemens.

May I be permitted, in concluding this note, to revert to the objection formulated by M. Faye, and to render it in some degree palpable by a numerical example? In an extensive work upon which I am engaged, upon the constitution of the stellar space, I naturally examine into the consequences that the resistance of a gas diffused in space would have upon the movements of the planets. From this work I extract an example relating to the application of analysis to the motion of our Earth. According to Laplace, the diminution or augmentation which one may attribute to the duration of our sidereal year 3000 years ago, taking into account the uncertainty of the observations, would be 90 seconds at the maximum (a modification of which, however, there is notbing to demonstrate the reality). Accepting a reduction of this amount as real, I inquire what density a gas would need to have to produce 
it; and I show that it would suffice if there were 1 kilogr. of matter in vapour in 700 thonsand millions of cubic metres-in other words, that the density would be $0.00000000000143 \mathrm{kilogr}$. It will be seen that we are far from the reduction to the $\frac{1}{200}$, and even to the millionth assumed by Mr. Siemens. If, instead of taking account only of the resistance opposed by such a gas to the motion of our planet, we direct our attention to the consequences which its existence would have upon that of our atmosphere, we find that, unless we multiply our 700 thousand millions of cubic metres by 10,000 , and reduce the density sought for to 0.0000000000000001 kilogr., our atmosphere would be in a few moments swept away by the pressure exerted abore by the interstellar gas.

M. Faye is perfectly justified in saying that it is not such or such a degree of rarefaction, but that it is the vacuum (of matter, of course) that the astronomer requires to ensure the stability of the movements that his analysis shows. This vacuum no doubt upsets the doctrine, supposed to be so undeniable, which ascribes all the phenomena of the physical world to movements and collisions of material atoms independent of each other. One day or another, no doubt, this doctrine will have to give up its existence, and its defenders will have to resign themselves to admit in the physical world something more than matter in motion. In a remarkable letter to Bentley, Newton said that one must be destitute of all aptitude for a serious philosophical discussion to suppose that between two bodies which seem to attract each other at an unlimited distance, there is not something which establishes this relation; but, he adds immediately, is this intermediary material or immaterial? This I leave to the reader to decide. With that great genius undoubtedly there was no uncertainty upon this latter point; but, perhaps justly, he refrained from putting before his contemporaries a solution which might have seemed incomprehensible to them, as it still is, apparently, to so many minds of the present day.-Comptes Remilus, November 6, 1882, p. 812.

REPLY TO M. FAYE'S OBJECTLONS TO MR. C. W. SIEMENS'S THEORY OF THE SUN, BY C, W.SIEMENS.

M. Faye, while approving, generally, of the physical part of my investigations, questions their application to astronomy, and for the following reasons:--

1. That the presence of a universal gaseous medium at a pressure of $\frac{1}{2000}$ atmosphere would oppose an excessive resistance to the movements of the planets; 2. That this vapour, thus distributed, would be gradually attracted towards the sun and would tend to angment its mass considerably.

Allow me to point out, as regards, in the first place, the second of M. Faye's objections, that the degree of diffusion supposed by me is such as may ensure the permanence of the statical equilibrium between the forces of expansion and diffusion on the one hand, and 